\author{
Military Technical College \\ Kobry El-Kobba, \\ Cairo, Egypt
}

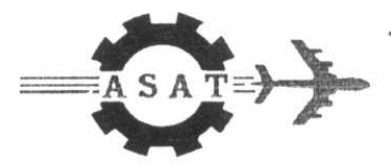

11-th International Conference

on Aerospace Sciences \&

Aviation Technology

\title{
EXPERIMENTAL AND THEORETICAL INVESTIGATION OF DYNAMIC BEHAVIOR OF OLEO PNEUMATIC CAR SUSPENSION
}
Z. A. IBRAHIM*
M. G. RABIE*
S. A. HEGAZY"**
I. A. ELSHERIF ${ }^{\cdots *}$

\begin{abstract}
The oleo pneumatic (hydropneumatic) car suspension with self-leveling system is an essential part for any controlled suspension in modern vehicles. Therefore, the performance of the hydropneumatic vehicle suspension has been studied in the present work.
\end{abstract}

A mathematical model for a hydropneumatic suspension composed of hydraulic accumulator, double acting shock absorber and power cylinder has been deduced. The mathematical model has been solved numerically, using the MATLAP simulink program, to predict the dynamic performance of the hydropneumatic suspension. Experimental tests using the MTS damper test system have been applied to validate the results. The experimental testing and theoretical results have been compared; good agreement between them has been found.

The developed mathematical model for the hydropneumatic suspension has been applied to a two-degree of freedom vehicle model representing the vehicle body and wheel assembly. The dynamic response of the vehicle body has been obtained. The effect of different construction parameters and working conditions on the dynamic response has been studied in order to obtain the optimum values of these parameters.

\section{KEY WORDS}

Vehicle suspension - Hydraulic accumulator - Shock absorber - Damping - Transient response - Dynamic behavior - Sprung mass.

\footnotetext{
${ }^{*}$ M.Sc. Eng., Egyptian Armed Forces.

** Prof., Egyptian Armed Forces.

*** Ph.D. Egyptian Armed Forces.

${ }^{\star * \star *}$ Ph.D, Egyptian Armed Forces.
} 


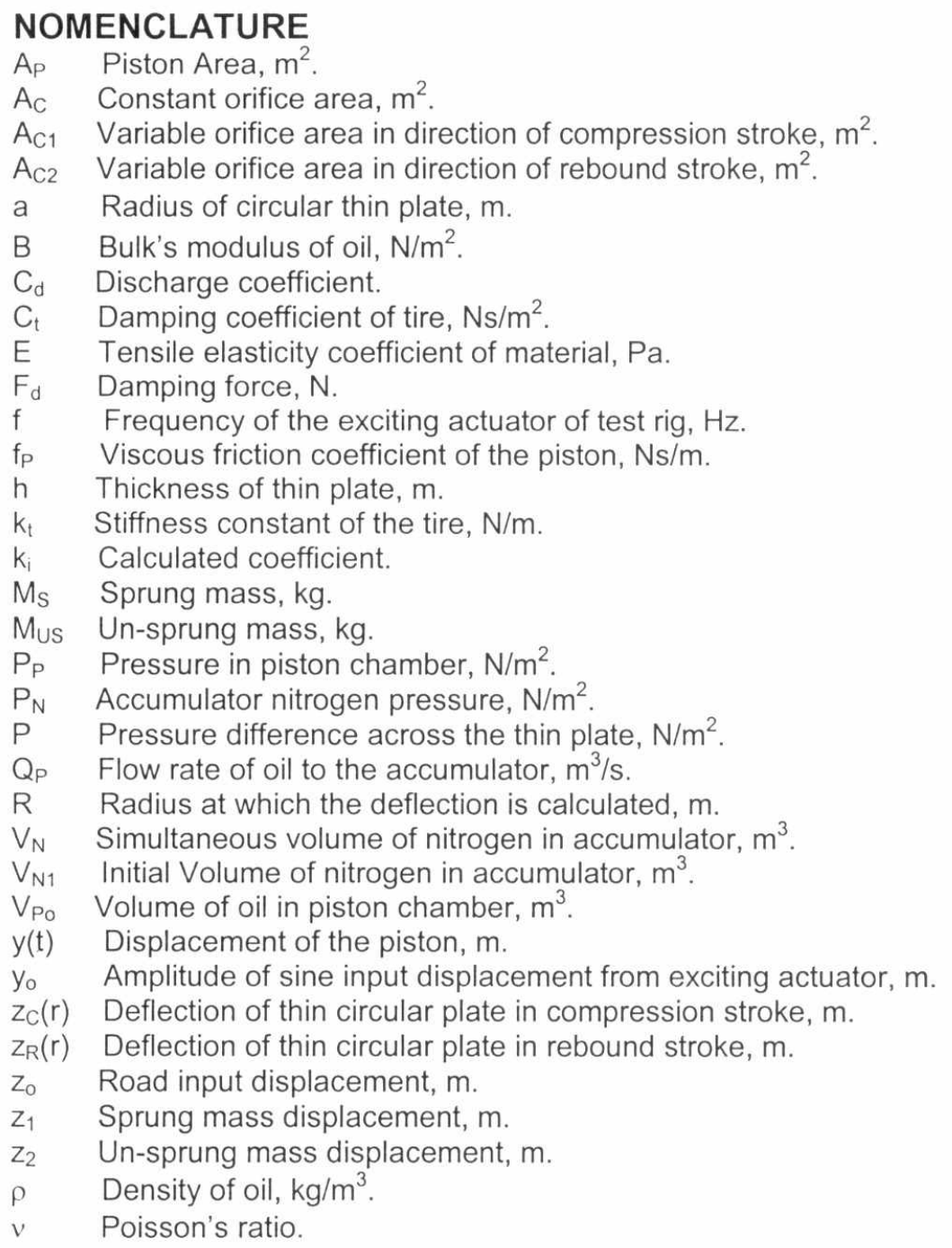

\section{INTRODUCTION}

Often the vehicle has to operate over a wide range of conditions and the choice of fixed stiffness and damping parameters of the suspension must be compromised. Some manufacturers attempted to overcome the problem by employing hydropneumatic suspension with self-leveling system It operates exactly as a passive suspension except an external energy is provided to maintain a constant ride height of the vehicle for different static loading. This system has a delay time of several seconds before any leveling corrections were made [1]. The main advantage is that none of the available workspaces is used up by the changes in static loading. Consequently, softer springs can be used to improve the ride comfort compared with a conventional system having the same available working space [2]. 
The potential improvement offered by self-leveling increases with the payload capacity of the vehicle. The air spring in the hydropneumatic suspension effectively isolates high frequency vibration compared with conventional coil spring [3].

\section{Modeling and simulation of hydropneumatic suspension}

The mathematical model of the studied hydropneumatic suspension unit is introduced in Fig. (1). The model takes into consideration the nonlinear behavior of friction between the moving parts and the variation of throttling area due to the deflection of circular thin plate. The deflection of the thin circular plate depends on the pressure difference across the plate.

The suggested mathematical model is simulated and solved by a digital computer to obtain the dynamic behavior by using the MATLAB 6.5 tool kit. simulation allows testing the suspension unit when subjected to sever conditions with high dynamic loads.

The mathematical model is introduced by applying the equations describe the dynamic behavior of the suspension unit, considering the following operating conditions and assumptions:

1 - The density and bulk modulus of the oil are assumed constant.

2 - The coefficient of the discharge is assumed constant.

3 - The variation of the viscosity of oil is neglected.

4 - There are no internal or external flow rate leakages.

5 - piston barrel of shock absorber is fixed and the piston is in the mid stroke.

6 - Assuming polytropic process for the nitrogen gas compression and expansion.

The road input displacement in the form of:-

$y(t)=y_{0} \sin (2 \pi \mathrm{ft})$

$\mathrm{dy} / \mathrm{dt}=(2 \pi \mathrm{f}) \mathrm{y}_{\mathrm{o}} \cos (2 \pi \mathrm{ft})$

Continuity of flow in the piston chamber.

$A_{P} d y / d t-Q_{P}-\left[\left(V_{P_{o}}-A_{P} y\right) / B\right] d P_{P} / d t=0$

Where $\left[\left(V_{p o}-A_{p} y\right) / B\right] d P_{p} / d t$ is a term considering the effect of the compressibility in piston chamber.

Flow rate through the damping orifices of shock absorber.

$Q_{p}=C_{d}\left(A_{C}+A_{C 1}+A_{C 2}\right) \sqrt{\left|2\left(p_{n}-p_{p}\right) / \rho\right|}$

Variable orifice area in compression stroke $\left(A_{C_{1}}\right)$.

$$
\begin{aligned}
A_{C 1} & =0 & & P_{P}<P_{N} \\
& =\pi d_{1} z_{C} & & P_{P}>P_{N}
\end{aligned}
$$

Deflection of the thin circular plate during compression stroke.

$z_{C}(r)=\left[k_{1} r^{2} / 2+k_{2} \ln r-(P / 2 D)\left\{\left(a^{2} / 2\right)\left[\left(r^{2} \ln r / 2\right)-\left(r^{2} / 4\right)\right]-\left(a^{2} r^{2} / 8\right)-\left(r^{4} / 32\right)\right\}\right]+k_{3}$

$\mathrm{k}_{1}=2.3 \mathrm{E}-3$ * $\mathrm{P}$

$\mathrm{k}_{2}=-1 \cdot 1 \mathrm{E}-7{ }^{*} \mathrm{P}$

$\mathrm{k}_{3}=7.8 \mathrm{E}-8$ * $\mathrm{P}$

$\mathrm{D}=\mathrm{Eh}^{3} / 12(1-v)$ 
Variable orifice area in rebound stroke $\left(A_{C_{2}}\right)$.

$$
\begin{aligned}
A_{C 2} & =0 & & P_{P}>P_{N} \\
& =\pi d_{1} Z_{R} & & P_{P}<P_{N}
\end{aligned}
$$

Deflection of the thin circular plate during rebound stroke.

$z_{R}=\left[k_{1} r^{2} / 2+k_{2} \operatorname{lnr} r(P / 2 D)\left\{\left(a^{2} / 2\right)\left[\left(r^{2} / n r / 2\right)-\left(r^{2} / 4\right)\right]-\left(a^{2} r^{2} / 8\right)-\left(r^{4} / 32\right)\right\}\right]+k_{3}$

Nitrogen gas pressure in the accumulator.

$\mathrm{P}_{\mathrm{N}}=\mathrm{P}_{\mathrm{N} 1}\left(\mathrm{~V}_{\mathrm{N} 1} / \mathrm{V}_{\mathrm{N}}\right)^{1.3}$

Volume of nitrogen gas in the hydraulic accumulator.

$V_{N}=V_{N 1}-\int Q_{P} d t$

Damping force generated in the suspension unit.

$F_{d}=P_{p} A_{p}$

\section{Experimental measurement of Hydropneumatic suspension.}

The characteristics of the hydropneumatic suspension unit are investigated experimentally. The experimental results are used to evaluate the validity of the proposed mathematical model and simulation program by comparing the experimental and theoretical results under similar conditions. The damper test system is used for measuring the dynamic characteristics of the suspension unit, as shown in Fig. (2). It consists of four main parts, load unit, hydraulic power supply, digital controller and P.C computer.

The characteristics of the Hydropnumatic suspension are measured using the sine road input displacement with frequency $2 \mathrm{~Hz}$ and amplitude $0.08 \mathrm{~m}$, and frequency $3 \mathrm{~Hz}$ with amplitude $0.04 \mathrm{~m}$ respectively. The hydraulic accumulator is charged with nitrogen gas at pressure $27 \mathrm{E} 5 \mathrm{~N} / \mathrm{m}^{2}$, for the purpose of experimental testing. The hand pump is used to raise the pressure inside the cylinder to $34 \mathrm{E} 5 \mathrm{~N} / \mathrm{m}^{2}$. The upper end of the suspension unit is connected to the force transducer in the crosshead of the test rig and the lower end is connected to the cylinder of electrohydraulic servo actuator with linear variable transformer to measure the input displacement for the suspension unit.

The Theoretical and experimental dynamic characteristics of hydropneumatic suspension unit include the variation of the damping force with piston velocity; piston displacement and the time are shown in Figs (3-5) at different frequencies.

\section{Theoretical prediction of vehicle dynamic characteristics}

The mathematical description of the quarter vehicle model with hydropneumatic suspension, as shown in Fig. (6), is deuced by applying the Newton second low for the sprung and un-sprung mass considering the following assumption,

1 -The vehicle body is assumed to be a single rigid body.

2-The wheel assembly and the part of mechanical linkage is concentrated in a single rigid mass.

3-The nonlinear mathematical model of the damping element and the gas spring are taken into consideration in mathematical model of the quarter car model.

4-The tire is represented in the mathematical model with linear spring and linear damper, it is assumed that the tire is contact to the road all the time.

5-The suspension travel is in the range of available rattle space. 
For the sprung mass;

$P_{p} A_{p}-M_{S} g-f_{p}\left(d z_{1} / d t-d z_{2} / d t\right)=M_{S} d^{2} z_{1} / d t^{2}$

For the un-sprung mass;

$K_{t}\left(z_{2}-z_{0}\right)+C_{t}\left(z_{2}-z_{0}\right)-P_{p} A_{p}-M_{U S} g-f_{p}\left(d z_{2} / d t-d z_{1} / d t\right)=M_{u s} d^{2} z_{2} / d t^{2}$

The simulation model is used to obtain the dynamic characteristics of the hydropneumatic suspension and study the effect of damping area, accumulator charging pressure, sprung mass and road input displacement.

\subsection{Effect of damping area of the shock absorber.}

The damping area of the shock absorber is changed in percentage of the original setting, at the same step input displacement. The dynamic response in the form of displacement and acceleration of the sprung mass are shown in Figs. 7(a), 7(b). The variation of the suspension working space at different damping areas with the same road input is shown in Fig. 7(c). The variation of the damping force, sprung mass acceleration and displacement with the damping area of the shock absorber are shown in Fig. 8, which present the following observations:

1 - The sprung mass displacement decreases with the decrease of damping area of the shock absorber.

2 - The acceleration of sprung mass increases with the decrease of damping area.

3 - The damping force increases with the decrease of the damping area.

4 - The suspension working space decreases with the decrease of the damping area.

\subsection{Effect of increase of vehicle body mass.}

The vehicle body mass is increased from $200 \mathrm{~kg}$ to $350 \mathrm{~kg}$ with step value $50 \mathrm{~kg}$, at the same input displacement. The dynamic response of the sprung mass is obtained in Figs. 9(a), 9(b), The variation of damping force, sprung mass acceleration and displacement with the vehicle body mass are shown in Fig. 10. Which present the following observations:

1 - The damping force increases with increase of sprung mass which improve the handling characteristics of the vehicle.

2 - The sprung mass acceleration decreases with the increase of sprung mass and this is increasing the comfort ability of passengers.

3 - The sprung mass displacement increases slightly with the increase of sprung mass.

4.3 Effect of hydraulic accumulator charging pressure.

The charging pressure of the hydraulic accumulator, which indicates the stiffness of the suspension, is increased from 0.7 to 0.8 and 0.9 of the working pressure $P_{p}$. the following results are shown in Fig.11.

1 - The damping force decreases slightly, with the increase of charging pressure

2 - The sprung mass displacement decreases slightly, with the increase of charging pressure.

3 - The sprung mass acceleration decreases with the increase of charging pressure, which improves the comfort ability of passengers.

\subsection{Effect of the road irregularities.}

The effect of road irregularities is studied to measure to what extent the suspension system achieves the isolation from the road roughness. The isolation is measured according to the following dimensionless relation, 


$$
\text { Isolation }=\frac{z_{1} \max \cdot-z_{0}}{z_{0}} \%
$$

The results are shown in Fig. 12, at step input displacement $10 \mathrm{~mm}$ the isolation percentage is $58 \%$, and at step input displacement $100 \mathrm{~mm}$ the isolation percentage is $32 \%$. It means that the isolation efficiency increased with the increase of road input displacement.

\section{Conclusion.}

The mathematical model for the hydropneumatic suspension has been developed and the dynamic characteristics have been obtained for step road input. The effect of constructional parameters, damping area and working variables; accumulator charging pressure, sprung mass, and road irregularities has been studied. The ride comfort increases with increasing of the damping area, the accumulator charging pressure (not exceed 0.9 from the working pressure), and sprung mass. The handling characteristics decrease with the previous parameters.

Therefore, there is a contradiction between the comfort ability of passengers, which require low sprung mass acceleration and the handling requirements, which require high damping force to resist the roll and bitch moments of vehicle body, due to the cornering and breaking reaction. There is also contradiction between the comfort ability and the improvement of ride characteristics, which require small amplitude of sprung mass vibration displacement. Therefore, an optimum design point which compromise between ride and handling according to the working conditions specially the available limited working space in vehicle suspension. This lead to the necessity of design active suspension with variable characteristics in which the damping and the stiffness of the suspension can be controlled according to the working conditions and the road irregularities.

\section{REFERENCES}

1 - J.Y. wong, Theory of ground vehicles, second edition, Wiley, New York, 1993.

2 - D.A.Crolla,G.Firth,D.Horton, An introduction to vehicle dynamics, printed lectures, Department of mechanical engineering, University of Leads, 1991.

3 -J. Konishi, Y. Shiralshi, K. Katada, H. Ito, M. Yokote,Development of Electronically Controlled Air Suspension System. S.A.E paper No. 881770.

4 -Salvador de las Heras, Esteve Codina, Gas compression process inside oleopneumatic suspensions, International Fluid Power Exposition and technical Conference, 23-25 April 1996.

5 -P. Dennis McNeely, The dynamic load-compensating fluid spring: an evaluation in vehicular suspension, International Exposition for power transmission and Technical conference, 4-6 April 2000.

6 -Igor Ballo, technical note: Properties of air spring as a force generator in active vibration control systems, Vehicle system dynamics, Vol. 35, No. 1, pp. $67-72$, 2001.

7 -Mauriclo Baldi, Paplo Siqueira Meirelles, Hydropneumatic suspension design ASME 2003 Design Engineering Technical conference and computers and Information in Engineering Conference, Chicago, Illinois, USA, September 2- 6, 2003. 


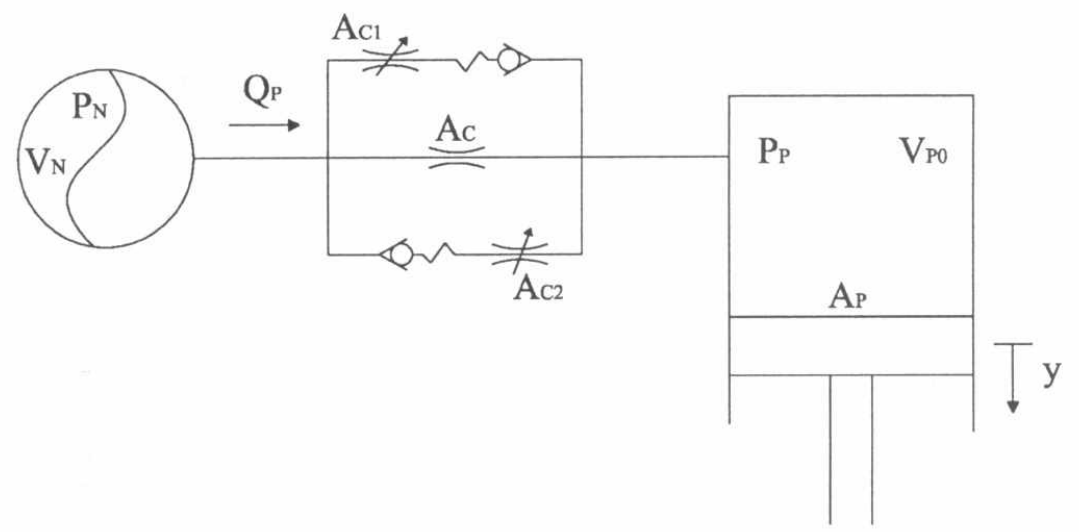

Fig. 1 Schematic drawing of the hydropneumatic suspension unit.

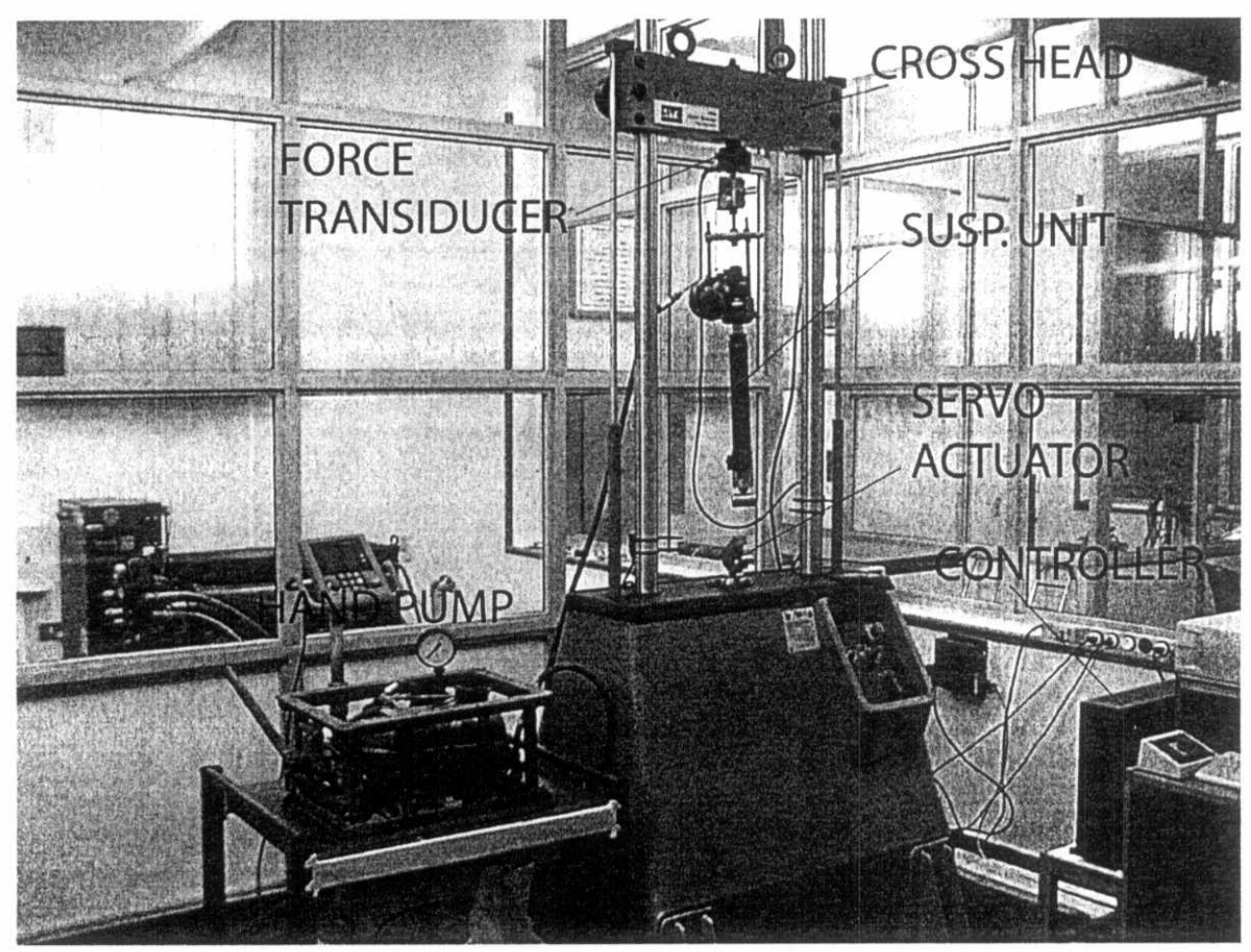

Fig. 2 Experimental test rig 


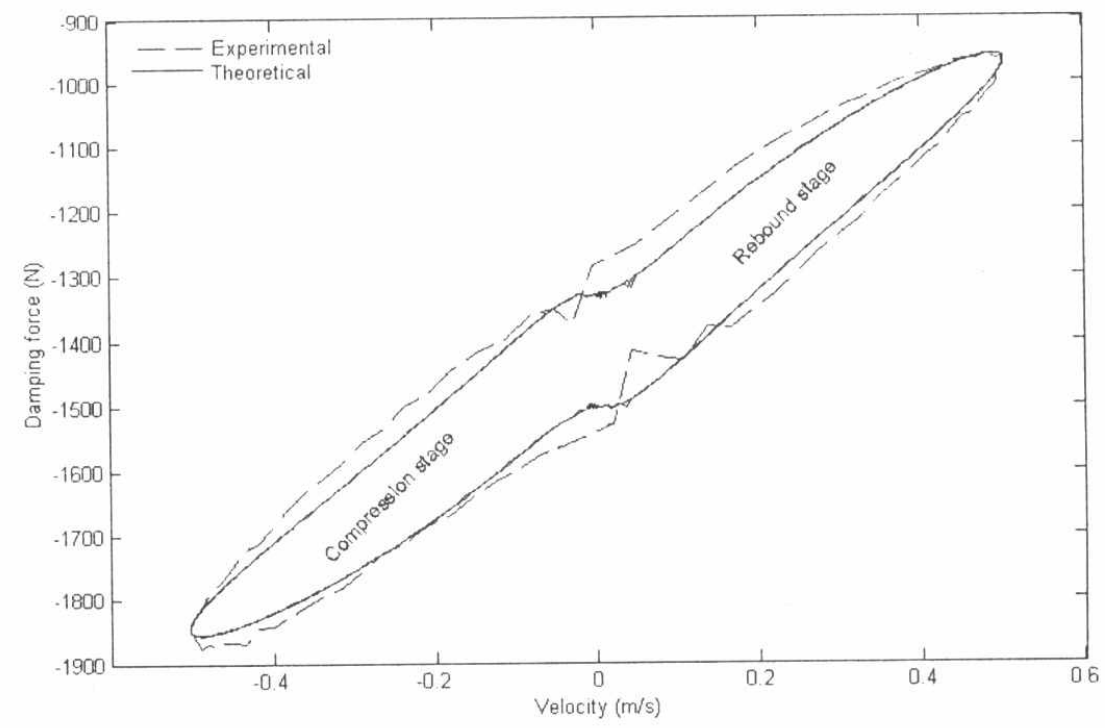

Fig.3-a Variation of damping force with piston velocity when the S.A is excited by sine input displacement with frequency $2 \mathrm{~Hz}$ and amplitude $80 \mathrm{~mm}$.

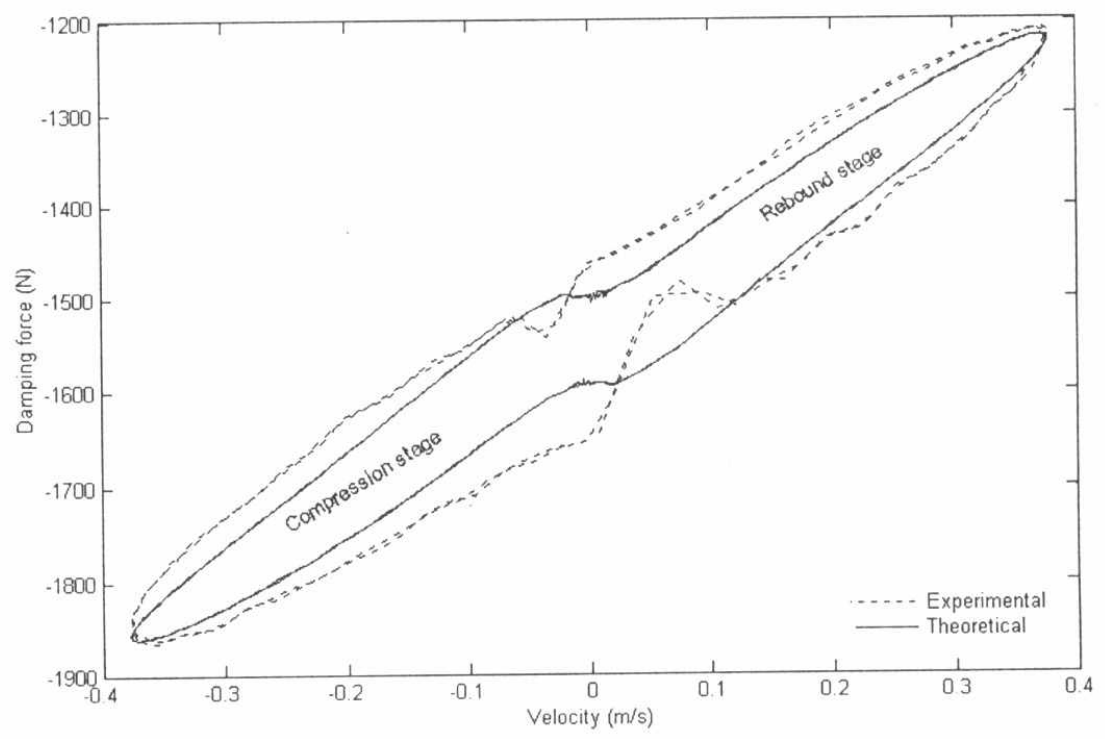

Fig. 3-b Variation of damping force with piston velocity of S.A when excited by sine input displacement with frequency $3 \mathrm{~Hz}$ and amplitude $40 \mathrm{~mm}$. 


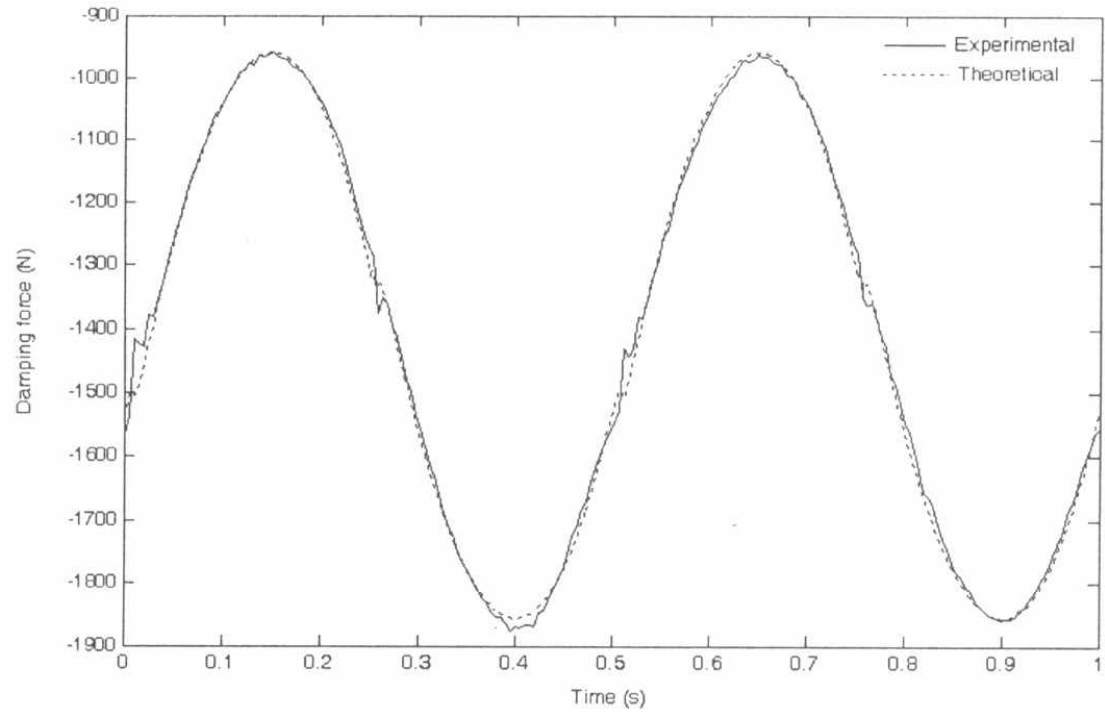

Fig.4-a Variation of damping force with time when the S.A is excited by sine input displacement with frequency $2 \mathrm{~Hz}$ and amplitude $80 \mathrm{~mm}$.

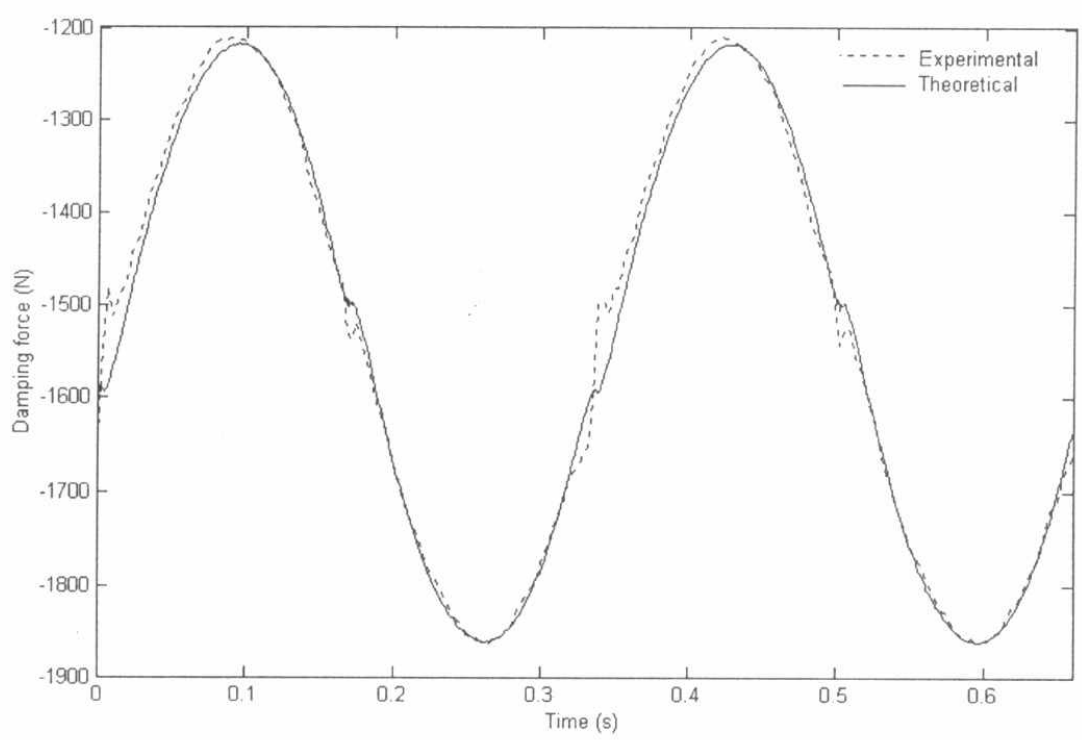

Fig. 4-b Variation of damping force with time when the S.A is excited by sine input displacement with frequency $3 \mathrm{~Hz}$ and amplitude $40 \mathrm{~mm}$. 


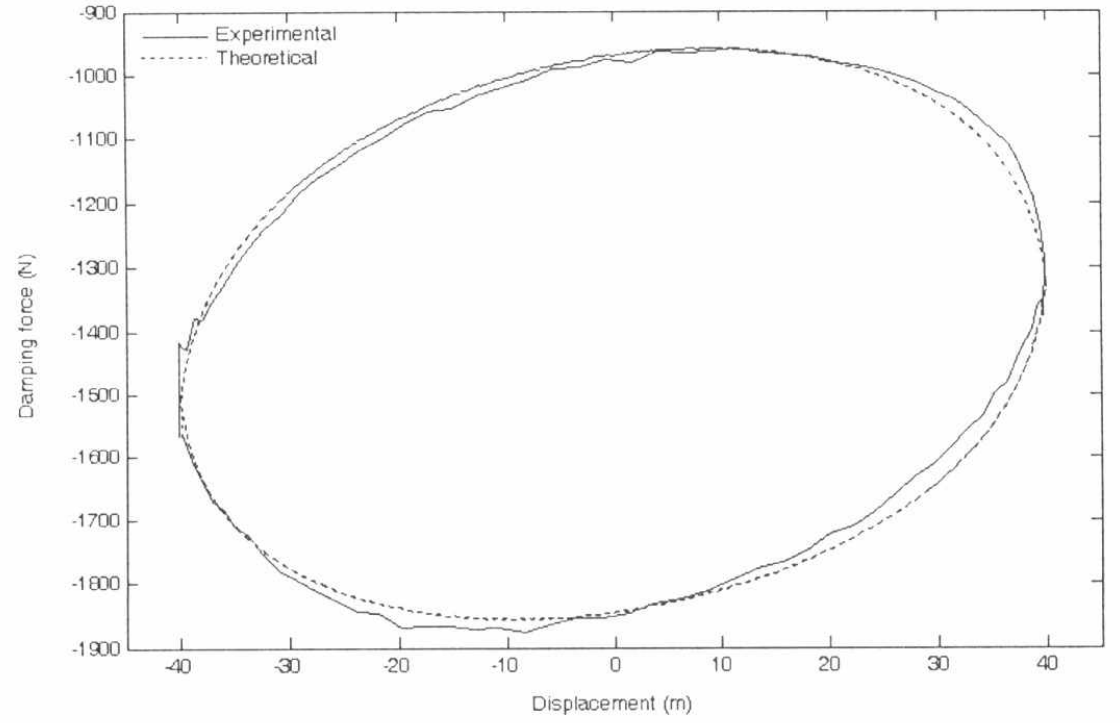

Fig. 5-a Variation of damping force with piston displacement when the S.A is excited by sine input displacement with frequency $2 \mathrm{~Hz}$ and amplitude $80 \mathrm{~mm}$.

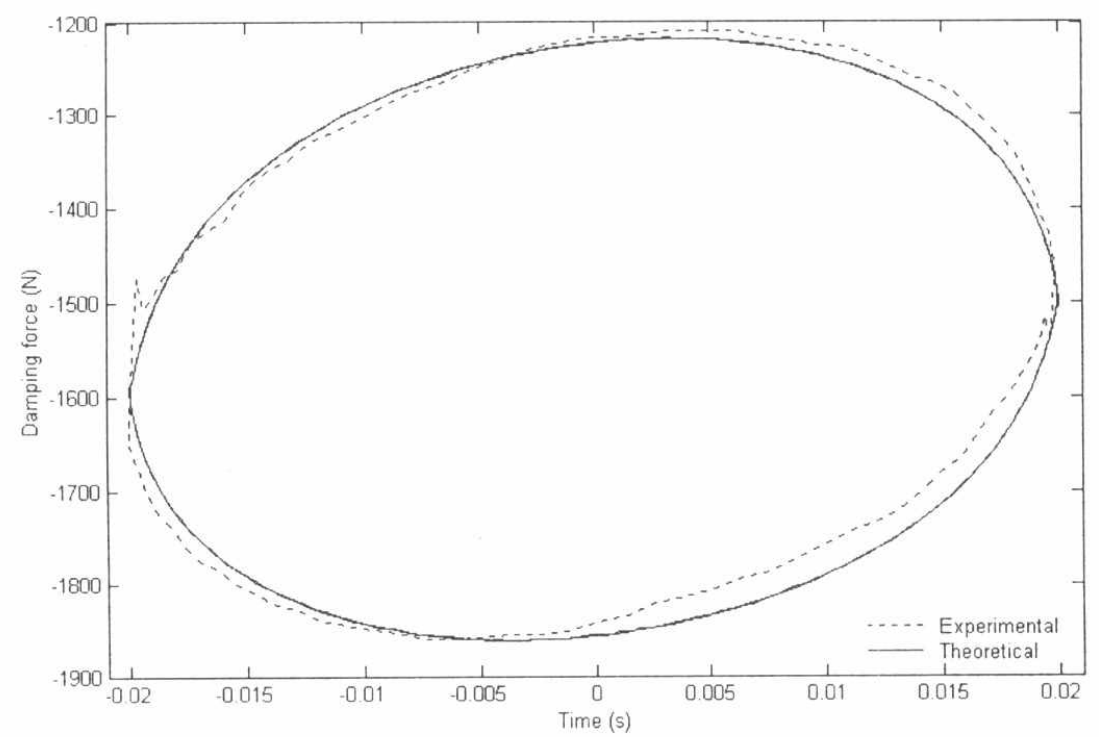

Fig. 5-b Variation of damping force with piston displacement of S.A when excited by sine input displacement with frequency $3 \mathrm{~Hz}$ and amplitude $40 \mathrm{~mm}$. 


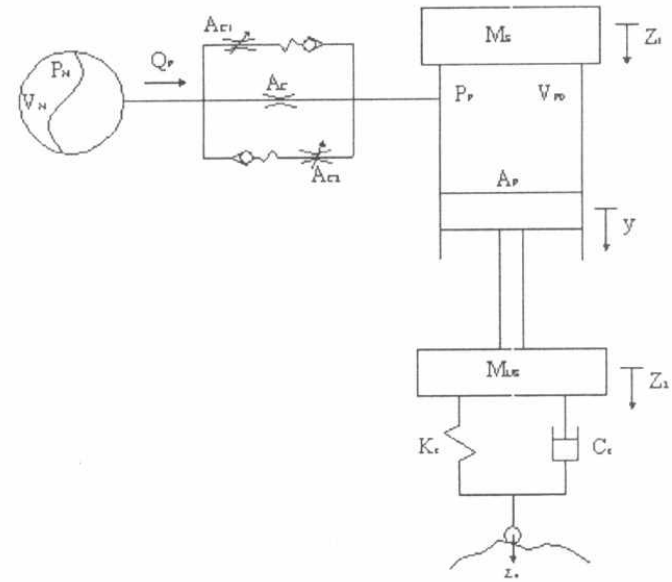

Fig. 6 Schematic drawing of quarter car model.

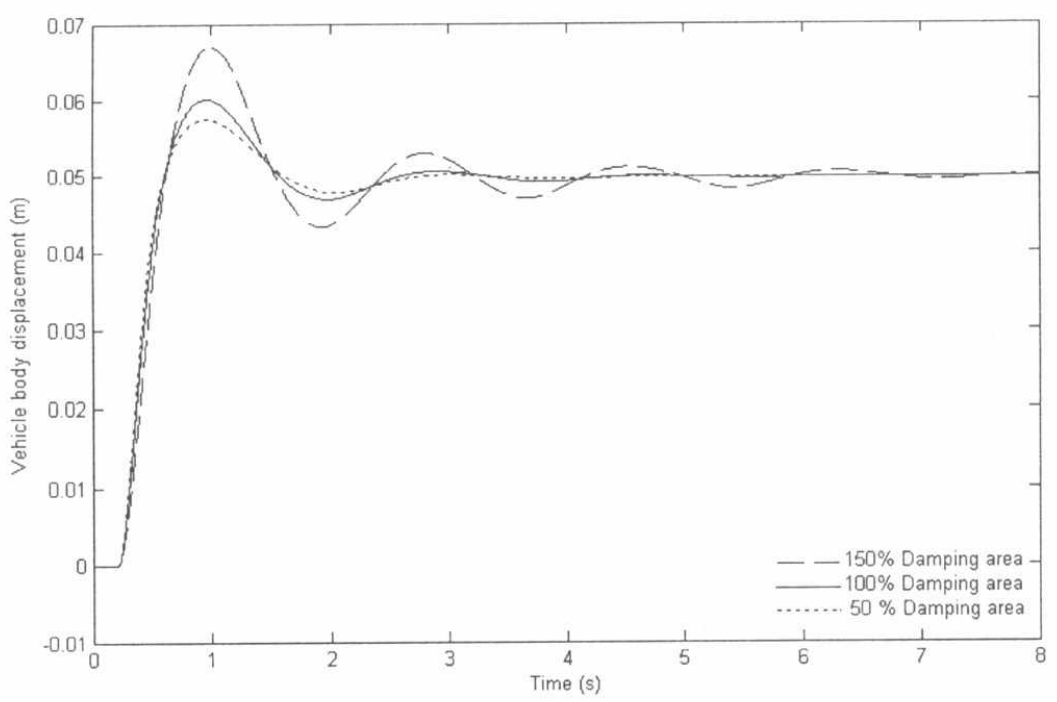

Fig. 7(a) The variation of sprung mass displacement with time at different damping areas of S.A. 


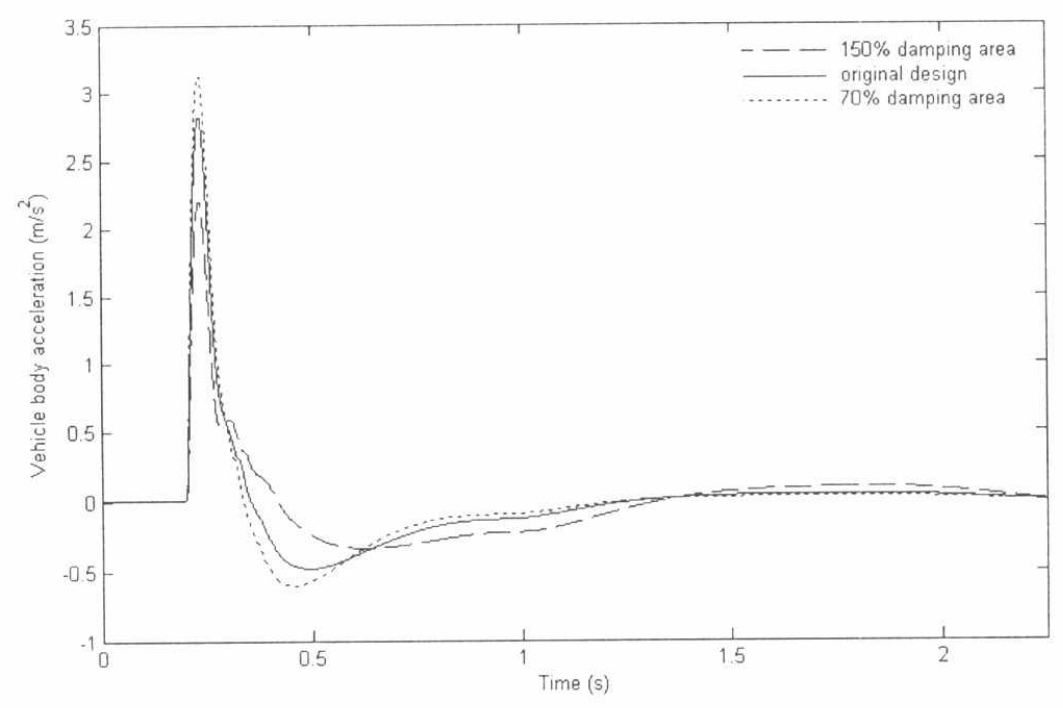

Fig. 7 (b) The variation of sprung mass acceleration with time at different damping areas of S.A

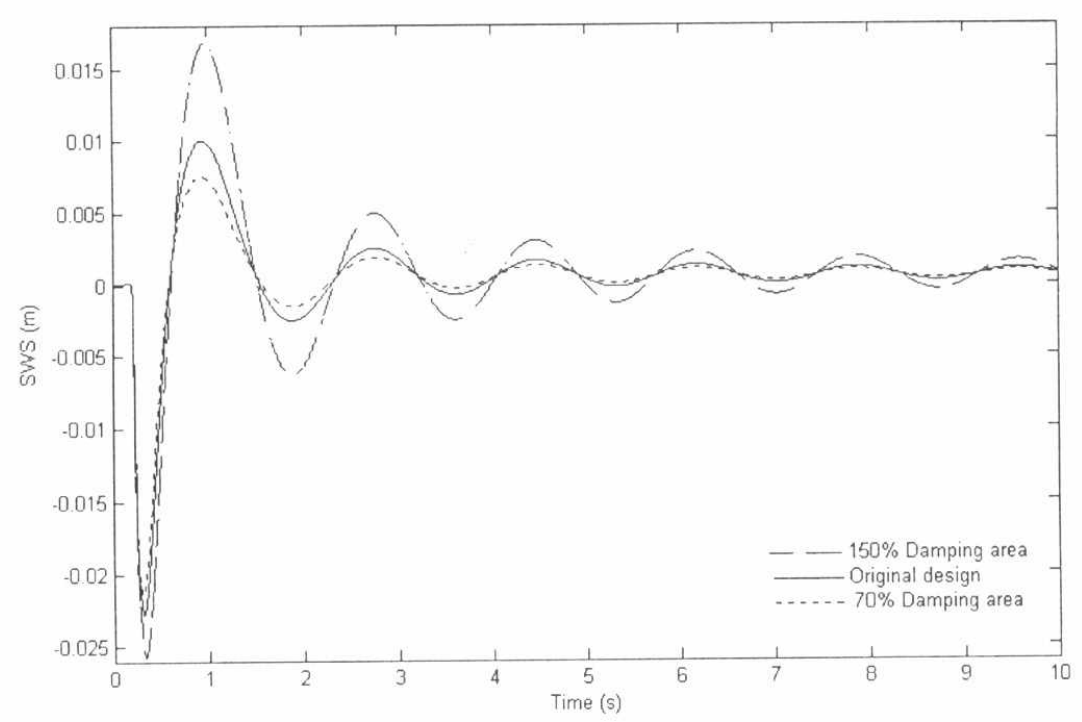

Fig. 7(c) Variation of the suspension working space at different damping areas with step input displacement. 

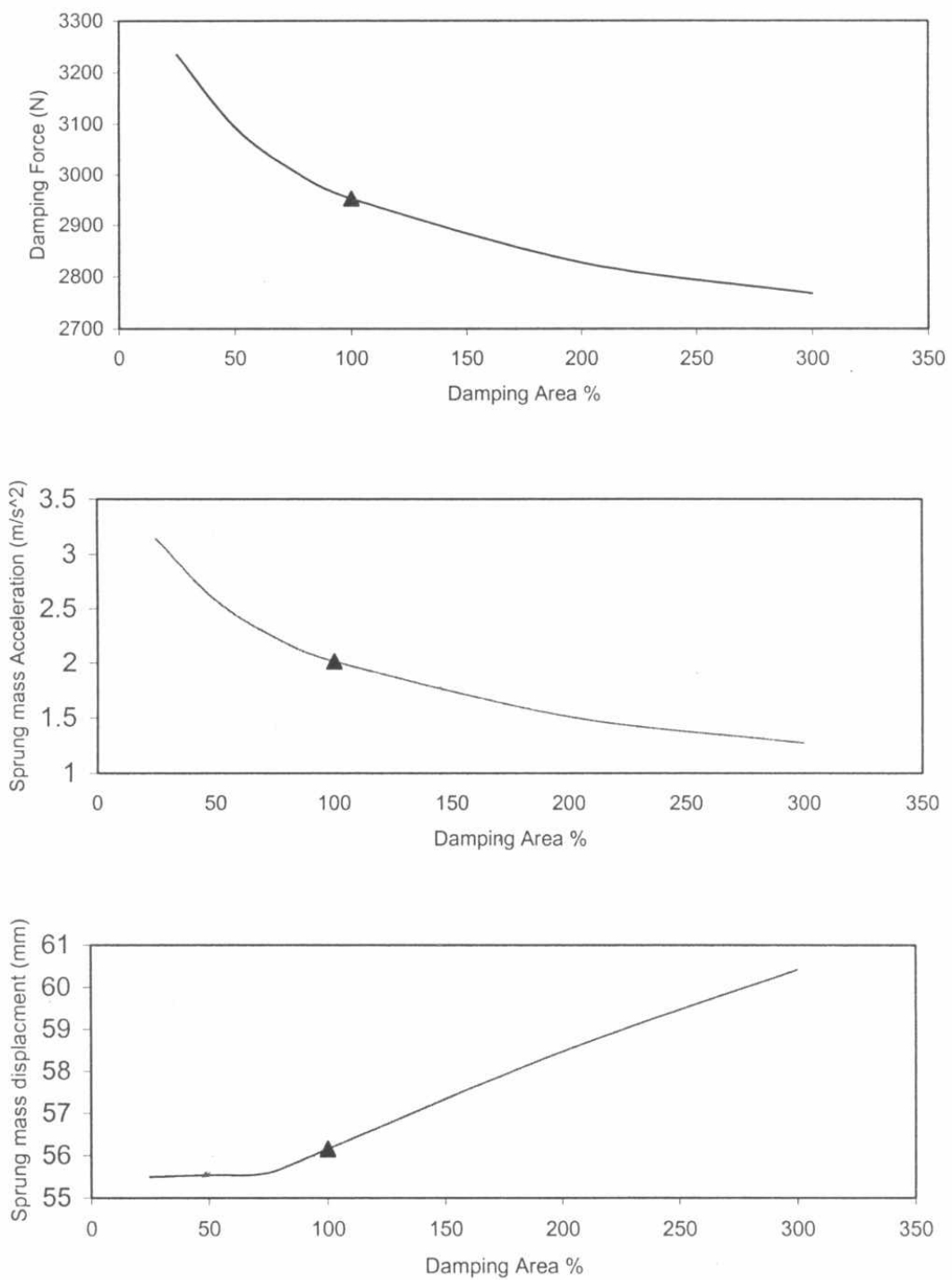

Fig. 8 Variation of damping force, displacement and acceleration of sprung mass with damping area 


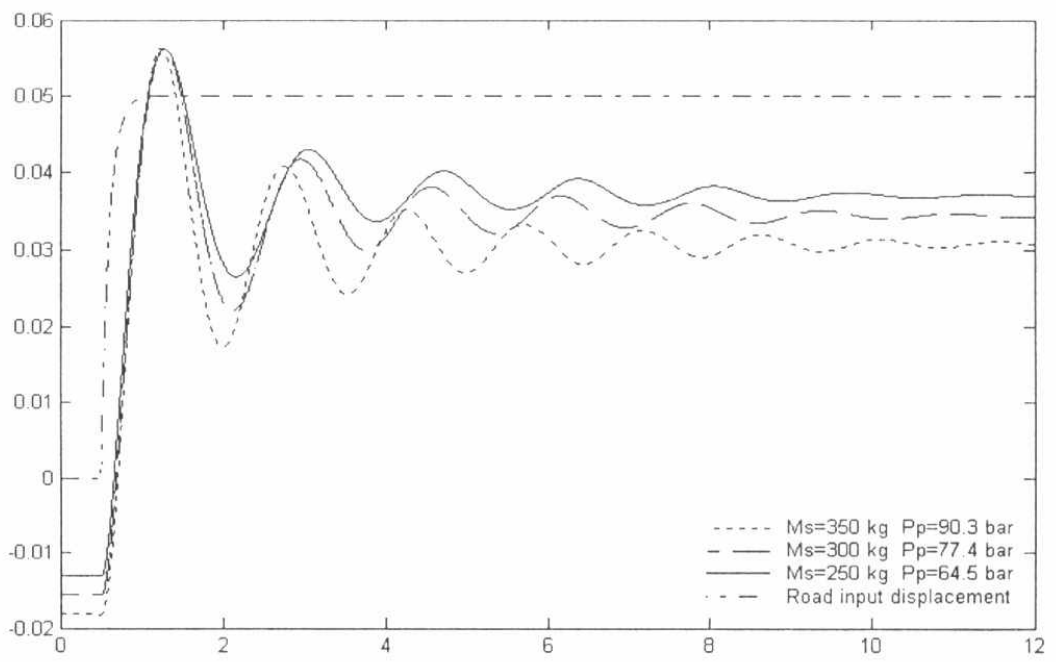

Fig. 9(a) The variation of the sprung mass displacement with time at different load pressures

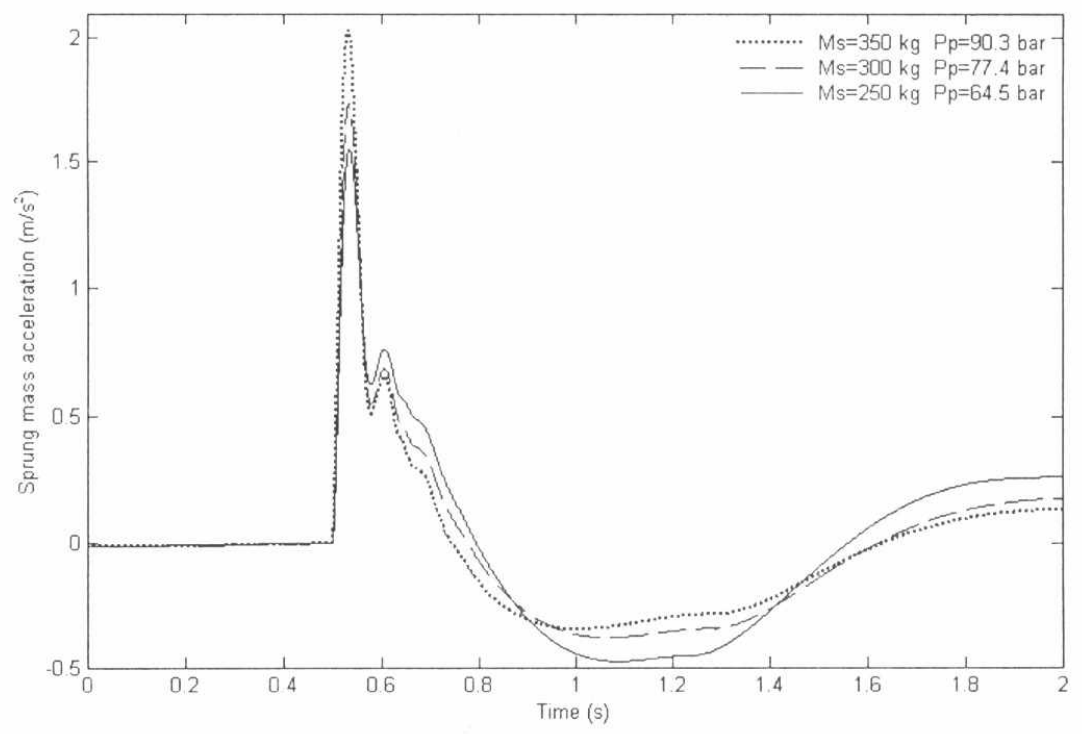

Fig. 9(b) The variation of the sprung mass acceleration with the time at different load pressures, 

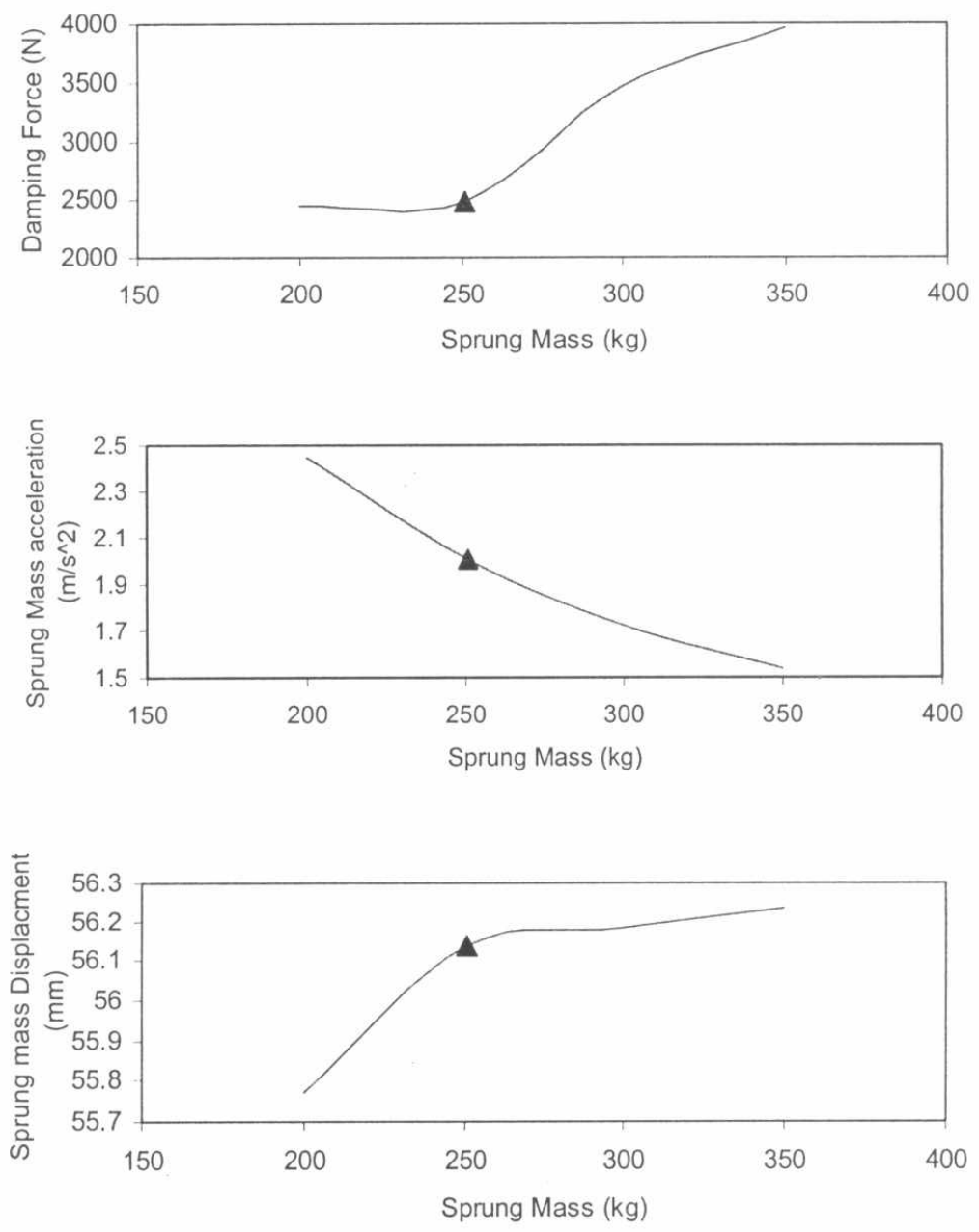

Fig. 10 Variation of damping force, displacement and acceleration of sprung mass with increase of sprung mass. 

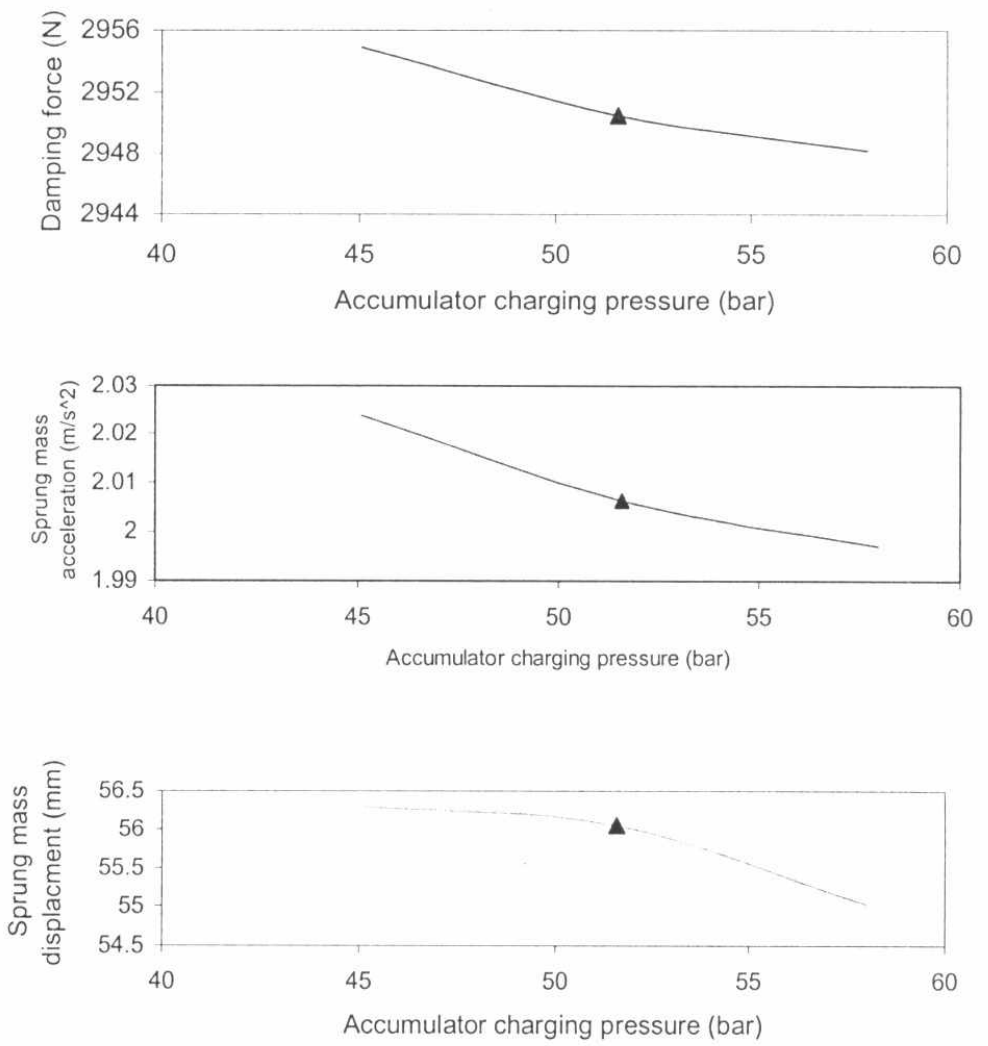

Fig. 11 Variation of damping force, displacement and acceleration of sprung mass with accumulator charging pressure.

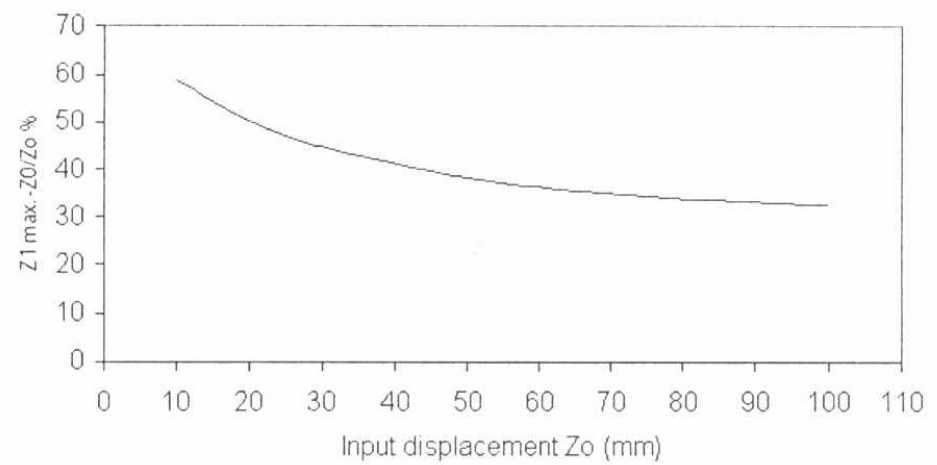

Fig. 12 Variation of sprung mass displacement with input road displacement. 